\title{
26. Medically assisted reproduction in developed countries: Overview and societal challenges
}

\author{
Jasmin Passet-Wittig and Martin Bujard
}

\section{INTRODUCTION}

Throughout history, people have experienced problems procreating, and have suffered because of it. However, people's options for treating infertility were rather limited before the advent of reproductive medicine. This field of medicine has received considerable public attention since the first baby was born after in-vitro fertilisation (IVF) in the United Kingdom in 1978. Methods of medically assisted reproduction (MAR) such as IVF help people with an unfulfilled desire to have a child. The barriers to procreation can be medical or social. Medical infertility is defined as the inability to establish a pregnancy after at least 12 months of regular, unprotected intercourse (Zegers-Hochschild et al. 2017). Social barriers to procreation include precarious employment, difficulties reconciling work and family life, and casual relationships. Moreover, social barriers to procreation that were previously seen as insurmountable, such as being in a same-sex relationship or having no partner, are becoming less significant because of reproductive medicine. As the scope of (potential) MAR users has expanded, reproductive medicine is no longer seen as simply 'curing' a medical problem, and thus challenges conventional understandings of family.

The use of reproductive medicine is closely intertwined with societal trends in fertility behaviour. The abovementioned social barriers to procreation often result in the postponement of childbearing to higher ages (Billari et al. 2006) and, in some cases, in unintended permanent childlessness (Kreyenfeld and Konietzka 2017). MAR can contribute to the recuperation of childbearing at higher ages (Habbema et al. 2015), and can have a sizeable effect on national birth rates (Geyter et al. 2018).

The use of reproductive medicine is increasing. According to global estimates that exclude China, 1,644 million treatment cycles resulted in 395,000 births in 2011 (Adamson et al. 2018). If China is considered, the number of treatment cycles increases to more than 2 million, and the number of births increases to approximately 500,000. Based on estimates that there were 5 million MAR births between 1978 and 2013 (Faddy et al. 2018) and the extrapolation of ICMART data, we project that the number of MAR births worldwide will surpass 10 million in 2020 or 2021. According to long-term projections, between 157 and 394 million people will owe their lives to treatments such as IVF at the end of the twenty-first century (Faddy et al. 2018). Today, nearly half of all MAR births in the world are in Europe and North America (Adamson et al. 2018). The economic dimension is also relevant: the IVF market generated revenues of $\$ 10.5$ billion in 2017 , and is expected to grow to $\$ 22.5$ billion in 2025 , with no signs that market saturation is approaching (Crawford and Ledger 2019).

These dynamics have a number of implications for families and societies. Most importantly, these developments affect the closely intertwined domains of legislation regulating which methods are allowed, access to treatments, and the reimbursement of treatment costs. Legal 
and financial boundaries limit access to treatments in different countries and for different subgroups. For (potential) users, medical developments and changing legal regulations on MAR can have profound effects on their individual and dyadic fertility decisions and life course plans. A thorough discussion of reproductive treatments needs to consider the various 'costs' of treatments for users. As well as being financially and physically draining, fertility treatments can be psychologically stressful (Greil 1997; Ying et al. 2016). In addition, on the societal level, the rise of MAR allows novel family forms to emerge. For example, reproduction can now involve more than two parties, such as when a male couple has a child with the help of a surrogate mother. New terms, statistical recording approaches, and laws may be needed to capture these new family forms.

This chapter provides an overview of reproductive medicine in developed countries, with a focus on the implications of MAR for individuals and societies. We start by introducing the relevant medical terminology and most important MAR treatments in Section 2. In Section 3 , we discuss how MAR is regulated in developed countries, including which methods are allowed, how the treatment costs are reimbursed, and how these factors are associated with the use of MAR. Next, in Section 4, we shift our perspective to explore the implications of infertility and fertility treatments for MAR users. In Section 5, we examine the health and the development of 'MAR families'. In Section 6, we discuss how fertility trends and MAR are interrelated. In the final section, we present several conclusions, and discuss avenues for social scientific research in the field of MAR.

\section{MEDICAL TERMINOLOGY AND OVERVIEW OF TREATMENTS}

The terms assisted reproductive technologies (ART), IVF, and MAR are frequently used to describe modern reproductive medicine, and are occasionally used synonymously. However, these concepts differ fundamentally. To avoid confusion about this terminology, we follow 'The international glossary on infertility and fertility care' (Zegers-Hochschild et al. 2017). The term medically assisted reproduction refers to 'various interventions, procedures, surgeries and technologies to treat different forms of fertility impairment and infertility' (2017, p. 1796). These include, but are not limited to, ART, a term that encompasses all procedures that include the handling of female and male gametes and embryos outside of the woman's body (Figure 26.1). ART includes IVF and treatments that are based on or related to IVF. Hormonal treatments and assisted insemination do not fall into this category. However, since these are important treatments that are frequently performed (for insemination, see Geyter et al. 2018), we prefer to use the broader term MAR. The popularity of the term ART has implications for research, as surveys such as the Generation and Gender Survey only consider ART use. Broadening the spectrum of treatments respondents are asked about in surveys could contribute to the development of a more comprehensive measurement of the actual use of reproductive medicine in societies.

In the following, we will give a brief introduction of the most important treatments. IVF involves the extracorporeal fertilisation of oocytes using sperm. The resulting embryos are then implanted in the woman's womb. If only one embryo is available for transfer, the woman undergoes what is called a single embryo transfer (SET). If more than one embryo is available and one is chosen for transfer, the woman undergoes what is called an elective single embryo 


\section{Medically Assisted Reproduction (MAR)}

\section{Assisted Reproductive Technologies (ART) \\ In-Vitro Fertilisation (IVF) \\ - Single Embryo Transfer (SET) \\ - Elective Single Embryo Transfer (eSET) \\ - Intracytoplasmatic Sperm Injection (ICSI) \\ - Frozen-thawed Embryo Transfer (FET)}

\section{Treatments based on IVF}

- Oocyte donation

- Surrogacy

-Embryo-donation

- Cryopreservation of gametes and embryos

(Social Freezing)

-Pre-implantation Genetic Testing (PGT)
Assisted Insemination

- Homologous sperm donation

- Heterologous sperm donation

Hormonal treatment

- Ovulation induction

- Controlled ovarian stimulation

- Ovulation triggering

Various interventions (e.g. myoma)

Source: Own representation.

Figure 26.1 Medical terminology: The difference between medically assisted reproduction and assisted reproductive technologies

transfer (eSET). Intracytoplasmatic sperm injection (ICSI) is a variation of IVF in which only a single sperm is injected into the oocyte. While this procedure is generally used to treat male factor infertility, the numbers of procedures performed exceed its prevalence, which is problematic (Adamson et al. 2018). The gametes used in both procedures can be either fresh or frozen. For a fresh cycle, the oocytes are retrieved in an operation after the woman has been treated with hormones. In order to reduce the burden for the woman, the remaining oocytes or embryos are often frozen for use in further treatments (cryopreservation). When a frozen embryo is transferred to a woman's uterus, this is called a frozen-thawed embryo transfer (FET).

Several treatments are based on or related to IVF. Oocyte donation, gestational surrogacy, and embryo donation are third-party reproduction treatments. Oocyte donation is a procedure in which oocytes are retrieved from an egg donor and then used to help other women get pregnant. Women who rely on oocyte donation cannot conceive due to a lack of ovaries by birth, a diminished ovarian reserve, or a genetic disease. Gestational surrogacy typically involves a surrogate who carries the pregnancy for the intended parents. The gestational surrogate is genetically unrelated to the child. If possible, both or at least one of the intended parents provide gametes (oocytes and/or sperm), which in the latter case can be combined with donor gametes. IVF is used to create the embryo, which is then transferred to the surrogate mother. Embryo donation often occurs within IVF treatment, because IVF is often used to create several embryos, only one or two of which are typically implanted, while the rest are frozen and can be donated if they are no longer needed by the intended parents. The cryopreservation of gametes and embryos can also be used to preserve them for a later point in time. This proce- 
dure allows women and men to have children after a medical treatment, such as chemotherapy. Recently, the cryopreservation of oocytes for non-medical reasons, which is referred to as 'social freezing', has become popular. Social freezing is done primarily to allow a woman to postpone births to higher ages, given that her ovarian reserve and oocyte quality will decline as she grows older. Pre-implantation genetic testing (PGT) is applied to embryos prior to implantation in the woman's uterus. The procedure is used to identify genetic diseases, but it can also be performed for other purposes, such as sex selection.

There are a number of other treatments that fit within the broad category of MAR. During an assisted insemination, the sperm of the woman's partner (homologous) or donor sperm (heterologous) are placed into the reproductive tract of a woman during ovulation to initiate a pregnancy. Hormonal MAR treatments include ovulation induction, ovarian stimulation, and ovulation triggering. These procedures are essential components of most ART treatments, but they can also be applied separately to assist women in getting pregnant. Other interventions, such as removing myoma, are also part of the broad field of MAR (Zegers-Hochschild et al. 2017).

\section{LEGISLATION, REIMBURSEMENT, AND USAGE OF MEDICALLY ASSISTED REPRODUCTION}

Taking into account the legislation regulating which MAR methods are allowed and how treatments are reimbursed is essential for understanding the situations of (potential) MAR users in a given country, and, thus, for understanding the ways in which families are formed with medical assistance. Viewed from the macro level, legislation provides the backdrop for individuals' or couples' decision making and actions regarding the use of MAR. In developed countries, the laws regulating which MAR methods are allowed and how they are reimbursed vary greatly. The situation in Europe has been described as 'legal mosaicism', which stems from cross-country differences in general moral values regarding 'the value of life, the welfare of the child, good clinical practice and safety' (Pennings 2009, p. 16). The legislators of each country have to make their own decisions about MAR, and navigate their way through conflicting interests in the application of these normative and ethical values. The laws and rules in place in a given country reflect what is considered acceptable in that society, and often represent a compromise of sorts. In the following, we focus on how MAR is regulated and reimbursed in highly developed countries, including in the European Union (EU) member states; the English-speaking countries of Australia, New Zealand, the United States, and Canada; and Japan.

\subsection{Methods Allowed}

In this section, we focus on legislation regulating which MAR methods are allowed. Due to space constraints, we are not able to cover another important aspect of MAR legislation: namely, who is allowed to use specific types of treatment. Governments restrict MAR access for different groups based on their relationship status and sexual orientation. The groups of people to whom such restrictions are often applied include single women, single men, lesbian couples, gay couples, transgender individuals, and intersex individuals. The decision to limit 
Table 26.1 Methods allowed in Europe, English-speaking countries, and Japan

\begin{tabular}{|c|c|c|c|c|c|}
\hline Country & Oocyte donation & Surrogacy & $\begin{array}{l}\text { Pre- implantation } \\
\text { genetic testing }\end{array}$ & $\begin{array}{l}\text { Selective foetal } \\
\text { reduction }\end{array}$ & Sex selection \\
\hline Australia & allowed $^{\mathrm{b}}$ & allowed $^{\mathrm{b}}$ & allowed $^{\mathrm{b}}$ & allowed $^{\mathrm{b}}$ & \\
\hline Austria & allowed $^{\mathrm{a}}$ & allowed $^{\mathrm{a}}$ & allowed $^{\text {a }}$ & allowed $^{\mathrm{b}}$ & allowed $^{\mathrm{b}}$ \\
\hline Belgium & allowed $^{\text {a }}$ & allowed $^{\mathrm{a}}$ & allowed $^{\text {a }}$ & allowed $^{\mathrm{b}}$ & not allowed $^{c}$ \\
\hline Bulgaria & allowed $^{\text {a }}$ & not allowed ${ }^{\text {a }}$ & allowed $^{\text {a }}$ & allowed $^{\mathrm{b}}$ & allowed $^{c}$ \\
\hline Canada & allowed $^{\mathrm{b}}$ & allowed $^{\mathrm{b}}$ & allowed $^{\mathrm{b}}$ & allowed $^{\mathrm{b}}$ & not allowed ${ }^{c}$ \\
\hline Croatia & allowed $^{\text {a }}$ & not allowed ${ }^{\mathrm{a}}$ & allowed $^{\text {a }}$ & & \\
\hline Czech Republic & allowed $^{\text {a }}$ & allowed $^{\mathrm{a}}$ & allowed $^{\text {a }}$ & allowed with conditions ${ }^{b}$ & not allowed ${ }^{\mathrm{c}}$ \\
\hline Denmark & allowed $^{\text {a }}$ & not allowed ${ }^{\text {a }}$ & allowed $^{\text {a }}$ & allowed with conditions ${ }^{c}$ & not allowed $^{\mathrm{c}}$ \\
\hline Estonia & allowed $^{\text {a }}$ & not allowed ${ }^{\text {a }}$ & allowed $^{\text {a }}$ & not addressed $^{c}$ & not allowed $^{\mathrm{c}}$ \\
\hline Finland & allowed $^{\text {a }}$ & not allowed ${ }^{\text {a }}$ & allowed $^{\text {a }}$ & allowed $^{\mathrm{b}}$ & allowed $^{\text {b }}$ \\
\hline France & allowed $^{\text {a }}$ & not allowed ${ }^{\text {a }}$ & allowed $^{\text {a }}$ & allowed $^{\mathrm{c}}$ & not allowed $^{\mathrm{c}}$ \\
\hline Germany & not allowed ${ }^{\text {a }}$ & not allowed ${ }^{\text {a }}$ & allowed $^{\text {a }}$ & not allowed ${ }^{\mathrm{b}}$ & allowed $^{\mathrm{c}}$ \\
\hline Greece & allowed $^{\text {a }}$ & allowed $^{\text {a }}$ & allowed $^{\text {a }}$ & allowed with conditions ${ }^{b}$ & allowed $^{\mathrm{b}}$ \\
\hline Hungary & allowed $^{\text {a }}$ & not allowed ${ }^{\mathrm{a}}$ & allowed $^{\text {a }}$ & allowed with conditions ${ }^{b}$ & allowed $^{\text {b }}$ \\
\hline Ireland & allowed $^{\text {a }}$ & not allowed ${ }^{\text {a }}$ & allowed $^{\text {a }}$ & not allowed ${ }^{\mathrm{b}}$ & allowed $^{\mathrm{c}}$ \\
\hline Italy & allowed $^{\text {a }}$ & not allowed ${ }^{\text {a }}$ & allowed $^{\text {a }}$ & allowed $^{\mathrm{b}}$ & not allowed $^{\mathrm{c}}$ \\
\hline Japan & allowed $^{\mathrm{b}}$ & not allowed $^{c}$ & allowed $^{\mathrm{b}}$ & not addressed ${ }^{\mathrm{b}}$ & practiced $^{\mathrm{b}}$ \\
\hline Latvia & allowed $^{\text {a }}$ & not allowed ${ }^{\text {a }}$ & allowed $^{\text {a }}$ & allowed $^{\mathrm{b}}$ & \\
\hline Lithuania & allowed $^{\mathrm{a}}$ & not allowed ${ }^{\text {a }}$ & allowed $^{\mathrm{a}}$ & not allowed ${ }^{b}$ & \\
\hline Malta & allowed $^{\text {a }}$ & not allowed ${ }^{\text {a }}$ & not allowed ${ }^{\text {a }}$ & & \\
\hline Netherlands & allowed $^{\text {a }}$ & allowed $^{\text {a }}$ & allowed $^{\text {a }}$ & allowed $^{\mathrm{c}}$ & allowed $^{\mathrm{c}}$ \\
\hline New Zealand & allowed $^{\mathrm{b}}$ & allowed $^{\mathrm{b}}$ & allowed $^{\mathrm{b}}$ & allowed with conditions ${ }^{b}$ & allowed $^{\mathrm{b}}$ \\
\hline Poland & allowed $^{\text {a }}$ & not allowed ${ }^{\text {a }}$ & allowed $^{\text {a }}$ & allowed with conditions ${ }^{b}$ & \\
\hline Portugal & allowed $^{\text {a }}$ & not allowed ${ }^{\text {a }}$ & allowed $^{\text {a }}$ & allowed with conditions ${ }^{b}$ & allowed $^{\text {b }}$ \\
\hline Romania & allowed $^{\text {a }}$ & allowed $^{\text {a }}$ & allowed $^{\text {a }}$ & allowed with conditions ${ }^{b}$ & allowed $^{\mathrm{b}}$ \\
\hline Slovakia & allowed $^{\mathrm{a}}$ & not allowed ${ }^{\text {a }}$ & allowed $^{\text {a }}$ & allowed with conditions ${ }^{\mathrm{c}}$ & not allowed $^{\mathrm{c}}$ \\
\hline Slovenia & allowed $^{\text {a }}$ & not allowed ${ }^{\text {a }}$ & allowed $^{\text {a }}$ & allowed $^{\mathrm{b}}$ & \\
\hline Spain & allowed $^{\text {a }}$ & not allowed ${ }^{\text {a }}$ & allowed $^{\text {a }}$ & allowed $^{\mathrm{b}}$ & allowed $^{\mathrm{b}}$ \\
\hline Sweden & allowed $^{\text {a }}$ & not allowed ${ }^{\text {a }}$ & allowed $^{\text {a }}$ & allowed with conditions ${ }^{c}$ & not allowed ${ }^{\mathrm{c}}$ \\
\hline United Kingdom & allowed $^{\text {a }}$ & allowed $^{\text {a }}$ & allowed $^{\text {a }}$ & allowed $^{\mathrm{b}}$ & allowed $^{\mathrm{b}}$ \\
\hline United States & allowed $^{\mathrm{b}}$ & allowed $^{\mathrm{b}}$ & allowed $^{\mathrm{b}}$ & allowed $^{\mathrm{b}}$ & allowed $^{\mathrm{b}}$ \\
\hline
\end{tabular}

Source: ${ }^{a}$ Calhaz-Jorge et al. (2020); ${ }^{\mathrm{b}}$ IFFS (2019); ${ }^{\mathrm{c}}$ IFFS (2016).

Note: PGT includes testing for monogenic disorders/chromosome structural rearrangements (PGT-M/SR) and testing for aneuploidies (PGT-A). If at least one type of testing is allowed in a country this country is marked as allowing PGT.

access generally reflects a set of political and societal compromises on the question of which family forms are considered acceptable, and, therefore, who is granted the right to have a child (Warnock 2002). For more information on the current policies on these issues, see IFFS (2019) or Calhaz-Jorge et al. (2020).

Insemination, IVF, ICSI, and FET are considered standard fertility treatment methods that are allowed in all of the countries covered here. The legality of other specific procedures differs between countries. Table 26.1 gives an overview of the legal status of oocyte donation, surrogacy, PGT, and methods for selective foetal reduction (SFR) and for sex selection. The information provided here is based on three sources. For several EU countries, there is up-to-date information reflecting the situation at the end of 2018 (Calhaz-Jorge et al. 2020). If information on a specific EU country is missing, and for the other countries, we use 
information from the most recent surveillance report on reproductive policy and practice published by the International Federation of Fertility Societies, which reflects the policies in effect in early 2018 (IFFS 2019); or we go back to the previous report, which reflects the situation in the autumn of 2015 (IFFS 2016).

The use of donated oocytes for ART treatments has increased in recent decades (IFFS 2019). This is in part because in many developed societies, women are delaying motherhood to ages at which their fertility is decreasing. All of the countries in Table 26.1 except Germany allow oocyte donation. One controversial issue regarding oocyte donation is the question of whether donors should receive compensation beyond being reimbursed for their time and expenses (IFFS 2019). Countries further differ in how they handle donor anonymity.

Surrogacy is a very contentious issue. For most gay couples, it is the only feasible way to have a child who is genetically related to one of the partners. Among the important themes that recur in debates over surrogacy are the exploitation of the surrogate mother, the well-being of the child, and how the different interests of the parties involved should be negotiated. In the majority of countries, surrogacy is prohibited. However, all English-speaking countries and some European countries permit surrogacy. Within the group of countries that allow surrogacy, there are important differences in the specific rules surrounding the practice. For example, the laws differ on whether only traditional surrogacy is allowed, ${ }^{1}$ whether the surrogate mother can be compensated, and who has access to the treatments.

PGT is now permitted in all countries for which information is available except Malta. From a medical perspective, PGT is an established medical practice (IFFS 2019). However, country-specific regulations on who is permitted to use it and the (medical) conditions for its use differ greatly. Two extreme examples illustrate these differences. First, in Germany, access to PGT is granted only to heterosexual couples with a high risk of severe inherited diseases. Approval by an ethical committee is required for PGT use, and the committee's decision is binding for the doctors at certified PGT centres. Fewer than 350 applications for PGT use were filed with these ethical committees in 2018 (Markmeyer 2019). Second, approximately one-third of all PGT treatments performed in Europe are done in Spain (Geyter et al. 2018). Unlike in Germany, any private IVF clinic in Spain can perform PGT (Pavone and Arias 2012).

Multiple pregnancies can be considered an unintended side effect of many MAR treatments. In some contexts, it has been and still is common practice to transfer more than one embryo to a woman in order to increase the likelihood that she will become pregnant. However, this practice increases considerably the risk of a multiple pregnancy, which can, in turn, pose serious risks for the mother and the children. SFR is a recognised method for reducing the risks and complications of multiple pregnancies. However, it could be considered preferable to reduce the number of embryos transferred by, for example, using eSET. SFR is fully permitted in 14 countries; it is allowed with conditions in 10 countries; and it is not allowed in three European countries (Germany, Ireland, and Lithuania).

Closely related to SFR is the practice of sex selection. With the advances in PGT, the sex of the embryo can be reliably predicted. In some countries, it is now a common practice to use this method for the gender selection of embryos. Other methods used for sex selection are sperm sorting and SFR. Of the 24 countries for which information on sex selection is available, 15 allow and/or practice some kind of sex selection, while nine prohibit it. Together with postnatal excess mortality, prenatal sex selection is a main driver of the skewed sex ratio at birth in Eastern Europe (Guilmoto and Duthé 2013). 


\subsection{Reimbursement Schemes}

The costs of treatments such as IVF and ICSI are considerable, and reimbursements by public authorities can substantially reduce out-of-pocket expenses. The availability of financial resources is an important factor in people's decisions about whether to seek fertility treatment across countries (United States: e.g., Farland et al. 2016; United Kingdom: e.g., Datta et al. 2016; Germany: e.g., Passet-Wittig 2017). Legal restrictions on who is eligible for reimbursement, and, more generally, high out-of-pocket expenses, likely result in social inequalities in who is able to use MAR.

Table 26.2 gives an overview of the reimbursement schemes in the EU member states. Most countries offer only partial coverage in the three main areas of expenses in an ART cycle: medication costs, doctor/medical costs, and laboratory costs. Partial coverage can mean that the patient receives a fixed amount of money or a share of the costs, which typically ranges between 10 and 70 per cent in these countries (Calhaz-Jorge et al. 2020). The variation in the rules is huge. Only Bulgaria, Croatia, and Greece offer full coverage of all treatment-related costs. There is large variation between countries regarding which areas of expenses are covered to which extent. For example Denmark, Estonia, and Hungary offer partial funding of medication costs and complete funding of doctor/medical costs and laboratory costs; while Belgium, the Czech Republic, and Latvia offer complete funding only for one area of expenses. In some countries one or two areas of expenses are not covered at all.

Furthermore, the numbers of cycles that are funded differ between countries (not shown in Table 26.2, see Calhaz-Jorge et al. 2020). In countries such as Germany, Italy, Spain, and Slovakia, a maximum of three cycles are funded per clinical pregnancy. In the Czech Republic, up to four cycles are funded if SET is used in the first two cycles (Calhaz-Jorge et al. 2020). There are several countries where treatment is not equally funded across the country: namely, in Denmark, Estonia, Germany, Italy, Spain, and the United Kingdom. Within these countries, there are regional differences in the rules on reimbursement, and, accordingly, in patients' out-of-pocket expenses. This variation can be hard to understand for those who live in the 'wrong' region.

Most countries have specified eligibility criteria for the funding of fertility treatment. It is common to set a minimum and/or maximum age for receiving funding. The variation in the maximum age for women is huge, ranging from 38 years in Latvia to 49 years in the Czech Republic. Some countries limit access to those with no children or in the case of a couple, have no children together. In Sweden, only one birth is covered irrespective of parity. In Portugal those that already have a MAR child can still get reimbursed for FET. Spain, Sweden, and Romania are the only countries that have set a maximum body mass index for women, above which no funding is provided.

These rules suggest that countries do not base their eligibility criteria on medical arguments alone - or, at least, they have very different interpretations of these arguments. One of the main motivations for restricting access or funding is to keep the costs down. Normative expectations regarding acceptable ways of building a family and acceptable family forms may also affect which individuals are supported in their attempts to have a child. 


\section{Research handbook on the sociology of the family}

Table 26.2 Funding schemes for European Union countries

\begin{tabular}{|c|c|c|c|c|c|c|}
\hline \multirow[t]{2}{*}{ Country } & \multicolumn{3}{|c|}{ Complete or partial funding } & \multirow{2}{*}{$\begin{array}{l}\text { Funding } \\
\text { equally across } \\
\text { country }\end{array}$} & \multirow{2}{*}{$\begin{array}{l}\text { Legal limits } \\
\text { for funding }\end{array}$} & \multirow{2}{*}{ Restrictions on funding } \\
\hline & $\begin{array}{l}\text { Medication } \\
\text { costs }\end{array}$ & $\begin{array}{l}\text { Doctor/ } \\
\text { medical costs }\end{array}$ & Laboratory costs & & & \\
\hline Austria $^{a}$ & partial & partial & partial & yes & yes & $\begin{array}{l}\text { max. age } 39 \text { for women and } 49 \\
\text { for men }\end{array}$ \\
\hline Belgium $^{a}$ & partial & partial & complete & yes & yes & max. age for women 42 \\
\hline Bulgaria $^{a}$ & complete & complete & complete & yes & yes & max. age for women 43 \\
\hline Croatia $^{a}$ & complete & complete & complete & yes & yes & max. age for women 42 \\
\hline $\begin{array}{l}\text { Czech } \\
\text { Republic }^{\text {a }}\end{array}$ & partial & complete & partial & yes & yes & max. age for women 49 \\
\hline Denmark $^{a}$ & partial & complete & complete & no & yes & $\begin{array}{l}\text { max. age for women } 40 \text {; only } \\
\text { women or couples with no own } \\
\text { children }\end{array}$ \\
\hline Estonia $^{\text {a }}$ & partial & complete & complete & no & yes & max. age for women 40 \\
\hline Finland $^{\mathrm{a}}$ & partial & partial & partial & yes & yes & $\begin{array}{l}\text { max. age for women } 40-45 \text { and } \\
\text { for men } 60 \text { (not in law but in } \\
\text { practice) }\end{array}$ \\
\hline France $^{a}$ & $\mathrm{n} / \mathrm{a}$ & $\mathrm{n} / \mathrm{a}$ & $\mathrm{n} / \mathrm{a}$ & yes & yes & max. age for women 43 \\
\hline Germany $^{a}$ & partial & partial & partial & no & yes & $\begin{array}{l}\text { max. age for women } 39 \text { and for } \\
\text { men } 49\end{array}$ \\
\hline Greece $^{\mathrm{a}}$ & complete & complete & complete & yes & no & \\
\hline Hungary ${ }^{a}$ & partial & complete & complete & yes & yes & max. age for women 45 \\
\hline Ireland $^{\mathrm{a}}$ & partial & no coverage & no coverage & & & \\
\hline Italy $^{\text {a }}$ & partial & partial & partial & no & yes & max. age for women 46 \\
\hline Latvia $^{\text {a }}$ & complete & partial & $\mathrm{n} / \mathrm{a}$ & yes & yes & max. age for women 38 \\
\hline Lithuania $^{\text {a }}$ & partial & partial & partial & yes & yes & max. age for women 42 \\
\hline Malta $^{\text {a }}$ & no coverage & $\begin{array}{l}100 \% \text { in public } \\
\text { centres; } 0 \% \text { in } \\
\text { private centres }\end{array}$ & $\begin{array}{l}100 \% \text { in public } \\
\text { centres; } 0 \% \text { in } \\
\text { private centres }\end{array}$ & yes & yes & $\begin{array}{l}\text { max. age for women } 48 \text {; only } \\
\text { childless women }\end{array}$ \\
\hline Netherlands ${ }^{a}$ & partial & partial & partial & yes & yes & max. age for women 42 \\
\hline Poland $^{\text {a }}$ & partial & no coverage & no coverage & yes & yes & max. age for women 40 \\
\hline Portugal $^{\text {a }}$ & partial & $\begin{array}{l}100 \% \text { in public } \\
\text { centres; } 0 \% \text { in } \\
\text { private centres }\end{array}$ & $\begin{array}{l}100 \% \text { in public } \\
\text { centres; } 0 \% \text { in } \\
\text { private centres }\end{array}$ & yes & yes & $\begin{array}{l}\text { max. age for women } 40 \text { and for } \\
\text { men } 60\end{array}$ \\
\hline Romania $^{a}$ & partial & partial & partial & yes & yes & $\begin{array}{l}\text { max. age for women } 40 \text {; only } \\
\text { childless; max. BMI } 30\end{array}$ \\
\hline Slovakia ${ }^{a}$ & partial & partial & partial & yes & no & \\
\hline Slovenia ${ }^{a}$ & $\mathrm{n} / \mathrm{a}$ & $\mathrm{n} / \mathrm{a}$ & $\mathrm{n} / \mathrm{a}$ & yes & yes & max. age for women 42 \\
\hline Spain ${ }^{\mathrm{a}, \mathrm{b}}$ & partial & partial & $\mathrm{n} / \mathrm{a}$ & no & yes & $\begin{array}{l}\text { max. age for women } 40 \text { and for } \\
\text { men } 55 \text {; BMI } 35 \text {; only couples } \\
\text { with no children together }\end{array}$ \\
\hline Sweden ${ }^{\text {a }}$ & partial & partial & complete & yes & yes & $\begin{array}{l}\text { max age for women } 39 \text { and for } \\
\text { men } 55 \text {; only one child will be } \\
\text { publicly funded; only child; max. } \\
\text { BMI (value n/a) }\end{array}$ \\
\hline $\begin{array}{l}\text { United } \\
\text { Kingdom }^{\mathrm{b}, \mathrm{c}}\end{array}$ & partial & partial & partial & no & yes & $\begin{array}{l}\text { max. age for women } 39-42 \text {; } \\
\text { 'postcode lottery' }\end{array}$ \\
\hline
\end{tabular}

Note: $\mathrm{BMI}=$ body mass index

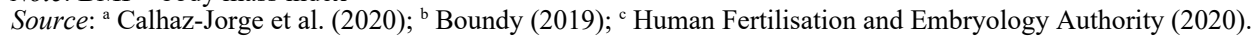




\subsection{Usage}

As with legislation and reimbursement schemes, there are large differences between European countries in the numbers of ART treatments performed. We report information on the number of treatment cycles per million women of reproductive age, which is available for 20 European countries with complete reporting of all clinics to the national register in 2014, 2013, or 2012 (see Figure 26.2). ART cycles refer to cycles of IVF, ICSI, frozen embryo replacement,

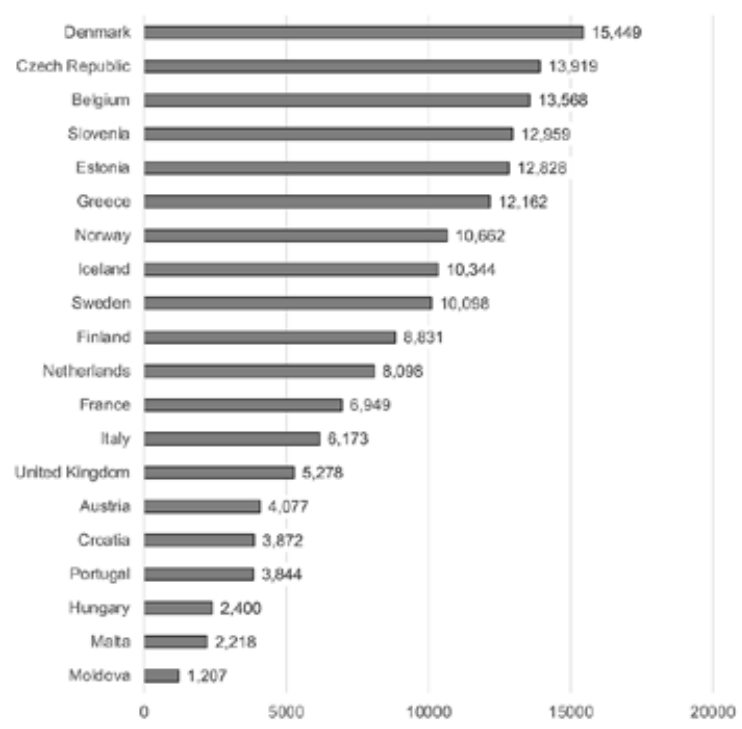

Note: ART cycles refer to IVF, ICSI, frozen embryo replacement, oocyte donation, in-vitro maturation, frozen oocyte replacement, and PGT combined.

Source:Values for Malta, Portugal, the United Kingdom, Italy, Netherlands, Finland, Iceland, Norway, Greece, Estonia, Slovenia, Belgium, the Czech Republic, and Denmark are from 2014 (Geyter et al. 2018); values for Moldova and France are from 2013 (Calhaz-Jorge et al. 2017); values for Hungary, Croatia, Austria, and Sweden are from 2012 (Calhaz-Jorge et al. 2016). Own representation.

Figure 26.2 Number of treatment cycles per million females of reproductive age (15-45 years) in European countries

oocyte donation, in-vitro maturation, frozen oocyte replacement, and PGT. The variation in the number of treatment cycles per million women among the countries in our sample is huge, ranging from 1,207 in Moldova to 15,449 in Denmark. It is noticeable that among the top 10 countries are five Scandinavian countries (Denmark, Norway, Iceland, Sweden, and Finland) and three Eastern European countries (Czech Republic, Slovenia, and Estonia). Intrauterine insemination is recorded less comprehensively than IVF. In 2014, 120,789 inseminations using partner's sperm and 49,163 inseminations with a donor's were recorded based on data from 25 and 21 countries, respectively (of 51 countries).

Usage of MAR depends on many factors, including, but not limited to, legislation and reimbursement schemes (Passet-Wittig and Greil 2021). A study by Präg and Mills (2017) showed 
that on the macro level, the factors that are highly predictive of the level of MAR utilisation in a given country include not just its affluence, but the normative acceptance of ART, as well as the size of religious groups and the extent of fertility postponement. Other authors have found that the total fertility rate and ART usage are positively associated (Kocourkova et al. 2014). Moreover, it appears that the generosity of reimbursement schemes is more relevant than the composition and size of the groups who are granted access (Chambers et al. 2012; Präg and Mills 2017). Präg and Mills argued that this is because the treatments are quite costly for everyone, which creates serious barriers to access for almost everyone in need of treatments.

If prospective parents need or want a procedure that is not available to them in their country - e.g., because the treatment is prohibited or access is restricted, it is too expensive, or there are long waiting times to receive it - they might consider travelling to another country for treatment (Ferraretti et al. 2010). Various labels exist for this phenomenon, including cross-border reproductive care or travel, and reproductive or fertility tourism. There are different destinations that prospective parents tend to seek out depending on the type of treatment needed. According to Salama et al. (2018), Belgium and Israel are major global markets for IVF; Spain and the Czech Republic are popular destinations for oocyte and embryo donation; Russia and the United States are common destinations for commercial surrogacy; the United States is often sought out for PGD and sex selection; and Denmark, Belgium, Germany, and the United States are popular destinations for fertility preservation. The people who travel abroad for such treatments represent a highly selective group. Obtaining fertility treatments abroad requires people to have sufficient financial resources to cover substantial out-of-pocket costs for the treatments themselves, as well as travel-related costs. Moreover, prospective parents need to be able to manage the 'logistics' of cross-border reproductive care.

Experts have pointed out the (medical) risks of reproductive travel (Ferraretti et al. 2010; Pennings 2002). One problem is that standards regarding the quality and the safety of treatments can vary. In the country of destination, the success rate might be lower, the risk of multiple pregnancies may be higher, and MAR users might not receive adequate information and counselling due to language problems.

\section{INFERTILITY AND TREATMENT EXPERIENCE}

In this section, we aim to provide an overview of the literature on the effects of infertility and fertility treatment on people's lives. We treat the experience of infertility and the experiences with medical treatment separately, recognising that infertility is not just a medical, but a social phenomenon. Moreover, since not everyone who experiences infertility seeks medical help, and not everyone who uses MAR is medically infertile (e.g., single persons or homosexual couples), these two groups do not overlap completely.

Despite the low birth rates in most European countries, most people want to have children. Thus, when people experience infertility, this central life goal appears to be - and potentially is - unattainable. The impact of infertility on the lives of women and men can be severe, and can affect various life domains (Brkovich and Fisher 2009; Greil 1997; Ying et al. 2015). It has been shown that infertile people experience more stress, depression, anxiety, and lower self-esteem than their fertile counterparts do. Infertility is also associated with social stigma and shame. Thus, individuals' relationships with their family, friends, and, most importantly, with their partner can be affected by infertility. Some people might keep their fertility problem 
a secret from family and friends, or be envious of the pregnancies of siblings or friends. It appears, however, that in most cases, the relationship with the partner is not at risk; i.e., most infertile couples experience conflict, but are able to manage the situation together, and may even come out of it strengthened. Women and men are affected by infertility somewhat differently, with the impact on a woman's life being consistently greater than the impact on a man's life. The reasons for these gender differences are not completely understood (Culley et al. 2013). It has been argued that the effect the couple's infertility has on the man is rather indirect, and is moderated through the effect it has on the female partner. Social expectations regarding parenthood are typically stronger for women than for men. Wischmann and Thorn (2013) observed that the impact of infertility on men is more pronounced in societies that are more traditional, and in which MAR is less accepted.

The effect of infertility on the psychological well-being of an individual or couple depends on whether they actually intend to have a child. Women who are currently trying to have a child experience greater stress than those who are not trying (Greil et al. 2011a). This is important because the medical definition of infertility is not explicit about the question of fertility intent. The non-use of contraception does not necessarily imply that the individual or the couple are explicitly intending to have a child. Thus, those identified as infertile according to the medical definition might experience no adverse effects. Nevertheless, the medical definition has been frequently used to identify infertile people in the general population. It would be advisable to include fertility intent in the medical definition of infertility. However, the group who can be identified using the medical definition might be too narrow. Irrespective of whether an individual has a medical problem, if the person perceives him/herself as having a fertility problem, $\mathrm{s} /$ he is experiencing the adverse effects of infertility described above, and is potentially at risk of seeking medical help (Passet-Wittig et al. 2020).

Infertility-related stress has often been investigated in clinical samples; i.e., samples of patients at fertility clinics. In such studies, it is impossible to sort out to what extent the patients' stress is due to the experience of infertility, or of fertility treatment. Moreover, this research tends to be focused on 'typical' prospective parents (i.e., heterosexual couples). There is evidence from longitudinal data that infertile women who receive fertility treatment have higher stress levels than those who do not (Greil et al. 2011b), which indicates that undergoing fertility treatment is distressing. Patients also tend to make psychological adjustments during fertility treatment (Rockliff et al. 2014; Verhaak et al. 2007). This might seem counterintuitive at first glance, because MAR provides hope to people whose chances of natural conception are low or non-existent. Thus, it is important to investigate what makes fertility treatment so burdensome. For women, most treatments involve the intake of hormones following a strict schedule (e.g., stimulation of ovary growth, induction of ovulation) and frequent doctor visits, which usually take place during regular working hours. The considerable amount of time people need to pursue fertility goals with medical help is a somewhat neglected factor ( $\mathrm{Wu}$ et al. 2013). In-vitro methods involve the collection of eggs from a woman's ovaries - an intervention that involves general anaesthesia - and the transfer of the embryo(s) to the woman's womb. Overall, patients' expectations before and during treatment are high. Waiting for the results is experienced as particularly stressful. MAR users who do not achieve their fertility goals are especially negatively affected. Moreover, as the treatments are costly, the financial pressure on patients can be high.

Like the infertility experience itself, the experience of fertility treatment is gendered (Rockliff et al. 2014; Verhaak et al. 2007; Ying et al. 2016). Compared with men, women 
have higher levels of anxiety and depression before and during treatment, and while waiting for the results. A central aspect of reproductive treatments is that it is usually the woman who is treated medically. In most cases, the man's active involvement in treatment is limited to the delivery of sperm for diagnosis or treatment purposes.

\section{HEALTH AND DEVELOPMENT OF 'MAR FAMILIES'}

The use of MAR implies the disconnection of sex and reproduction. When the genetic parents and the social parents are different, the traditional understanding of what constitutes a family is called into question. Families created by MAR have been emerging as a new category. This new category includes numerous family forms that typically differ along one or more of the following dimensions: (1) genetic relatedness to the parents, (2) number of parents, (3) sex of the parents, and (4) sexual orientation of the parents (Golombok 2015). Treatments such as IVF and insemination can be combined with a surrogacy and with donor materials (semen, oocytes, and embryos) that may or may not be provided anonymously. Users of MAR can be heterosexual couples, lesbian or gay couples, and single women or men. More than two parties might be the parents: for example, a lesbian couple may have a child with a male friend. Treatments might take place in the home country of the intended parents or abroad. All these options add to the complexity of the families created with MAR.

How numerous are these new family forms? There are no numbers or estimates of the relationship status of MAR users in ART register data. Social science surveys could provide such information, but questions about MAR are seldom included in such surveys - or, if they are included, the prevalence of MAR use is found to be so low that the information cannot be interpreted meaningfully. It can be assumed that, globally, heterosexual couples make up the majority of users, as they represent the only group with access in all countries. However, regulations are changing, and there are several countries that no longer block access for same-sex couples and single individuals. Globally, access to treatment for single women and lesbian couples appears to be better accepted than access to treatment for single men and gay couples (IFFS 2019). It needs to be considered, however, that men de facto cannot use most treatments themselves, and surrogacy is controversial.

MAR is still an emerging field. Thus, knowledge about the implications of MAR for children and their families, and for societies, remains very limited. There is, however, considerable research on the well-being of children conceived with MAR over their life course. In the research on the children's general health, short- and long-term effects need to be differentiated. It is well established that compared with naturally conceived children, children conceived with MAR are more likely to have adverse birth outcomes, such as lower birth weight, pre-term birth, perinatal death, and admission to postnatal intensive care (Halliday 2007), and a higher prevalence of neurological problems (Ludwig et al. 2006). Interestingly, studies that have compared MAR-conceived singletons and twins with their naturally conceived counterparts have shown that the perinatal outcomes are worse for MAR singletons than for MAR twins (Helmerhorst et al. 2004). The reasons why this might be the case are not clear. The authors of the review pointed out, however, that on no account does this make a multiple pregnancy a desirable outcome. Studies on the long-term health effects of MAR found some evidence of increased risk of cardiovascular and metabolic problems in MAR children (Hart and Norman 2013a). For all of the health problems observed among MAR children, it is not clear whether 
the increased risk is related to the treatment itself, to factors associated with the infertility of the mother, or to the adverse birth outcomes mentioned above.

The literature suggests that compared with their naturally conceived counterparts, children conceived with MAR are not more likely to have major mental health problems during childhood and adolescence (Golombok 2015; Hart and Norman 2013b; Wagenaar et al. 2008), and that there are no differences depending on the use of donor conception (Ilioi and Golombok 2015). The latter factor is important, as it could be assumed that a child being told that $\mathrm{s} / \mathrm{he}$ lacks a genetic link to at least one parent would experience an impact on his/her psychological well-being. In this context, it is noteworthy that adolescents conceived through reproductive donation who knew about their origin did not report having negative feelings about their conception (Zadeh et al. 2018). As Hart and Norman (2013b) pointed out, there is only preliminary evidence of increased risks of clinical depression and attention deficit disorder among MAR children, which warrants further investigation. Importantly, the quality of parent-child relationships does not appear to differ between MAR-conceived children and naturally conceived children. The existing studies that have compared the cognitive functioning and the school performance of IVF and spontaneously conceived children found no significant differences between them (Hart and Norman 2013b; Wagenaar et al. 2008).

Overall, the existing evidence seems reassuring; i.e., it appears that from a medical and a social-psychological perspective, having been conceived through MAR is not harmful for children. It should, however, be noted that it is difficult to identify longer-term effects of MAR because of the sheer number of possible confounders and difficulties in establishing the appropriate control groups. For example, while a study found that IVF-conceived children performed better in school from grade 3 to grade 11 than naturally conceived children (Mains et al. 2010), the authors were not able to control for factors that are known to be relevant for explaining school performance, such as the parents' socio-economic status, education, and age. Moreover, the implications of MAR for children's mental health might not reveal themselves until adolescence or early adulthood, if the information about how they were conceived is not disclosed to them until they are older. The United Kingdom now recommends that parents disclose such information at pre-school ages to secure the child's right to know his/her genetic heritage (Nuffield Council on Bioethics 2013).

Nonetheless, beyond shedding light on the direct effects of assisted reproduction, studies on the various family forms created by MAR do provide new insights into the ways in which families affect children's development and well-being, and, in particular, into the effects of family structure and family processes. In her book on new family forms, Golombok $(2015$, p. 202) concluded that 'family structure - including the number, gender, sexual orientation and genetic relatedness of parents, as well as their method of conception - does not play a fundamental role in children's psychological adjustment or gender development'. According to Golombok (2015), family structure has a rather indirect effect through its impact on family processes and dynamics, including on the well-being of the parents and the quality of relationships within the family. These family processes could be different in families created with the help of donor materials, and social stigma could also play a role. More research on these issues is needed. 


\section{DEMOGRAPHY AND MEDICALLY ASSISTED REPRODUCTION}

\subsection{Postponement of Births and the Increasing Demand of Medically Assisted Reproduction}

Since the onset of the second demographic transition (Lesthaeghe 2010) in the 1960s and 1970s in Europe, North America, and Australia, births have been increasingly postponed. This trend has been attributed to a combination of factors, such as rising education and later entry in the labour market; the stratification and differentiation of occupations in the service sector, which increased the length of the on-the-job qualification phase; emancipation and changing gender roles; secularisation and value changes; as well as the separation of sex and reproduction following the introduction of modern contraceptives (Buchholz et al. 2008). In addition, the careers of both partners increasingly have to be considered when couples make fertility decisions. Thus, labour career uncertainty can result in the postponement of births, especially for highly educated women (Kreyenfeld 2010).

The phenomenon of the postponement of births is relevant for MAR because women are increasingly trying to start their fertility biography at ages at which fecundity is already decreasing (Dunson et al. 2004). Thus, postponement amplifies the demand for MAR, especially in subgroups such as highly educated women and their partners. The postponement of births manifests itself in the mean age at childbearing (MAC). For Western European countries, the United States, Canada, Australia, and Japan, the low point of the MAC since World War II was reached in the 1970s, at 25 to 28 years (OECD Family Database 2019). In Eastern European countries, the low point of the MAC was reached in the 1980s or 1990s, at 23 to 25 years. In the OECD countries, the MAC was 27.4 years in 1990, and had increased to 30.6 years by 2017. The increase in the MAC since 1990 has been substantial in most countries: e.g., by at least two years in Finland and the Netherlands; and by as many as five years in East Germany, Estonia, Korea, and the Czech Republic (Figure 26.3). The most recent data show that the countries with the highest MAC are Japan at 32.0 years, Ireland and Spain at 32.1 years, and Korea at 32.6 years. The increase in the MAC is reflected in the increasing ages of the women who seek help in infertility clinics. This is due not only to the increasing problems women encounter when trying to procreate at later ages, but also to normative expectations regarding the ideal age for having a first child (Bujard and Diabate 2016). Globally, the share of women treated with IVF and ICSI who were aged 40+ was 24.0 per cent in 2011 (Adamson et al. 2018).

The mean age at first birth (MAC1) is probably even more relevant for MAR than the MAC, because many of the women who seek medical help are childless. However, MAC1 data are not available for many countries, and particularly for the 1970s. In 2017, the MAC1 ranged from 26.1 in Bulgaria to 31.6 in Korea, and the unweighted country average was 28.9 (OECD Family Database 2019). However, within the countries, the postponement patterns differ greatly by social strata and education. For reasons explained above, the MAC1 for highly educated women is higher than it is for other educational groups. Based on decomposition analyses for the United Kingdom, France, and Belgium, Neels et al. (2017) showed that the increase in educational attainment accounted for 57 to 74 per cent of the increase in MAC1. Calculations based on German Microcensus data reveal that the proportion of first births after age 35 increased between 2002-2004 and 2012-14 by 40 per cent for highly educated women. 


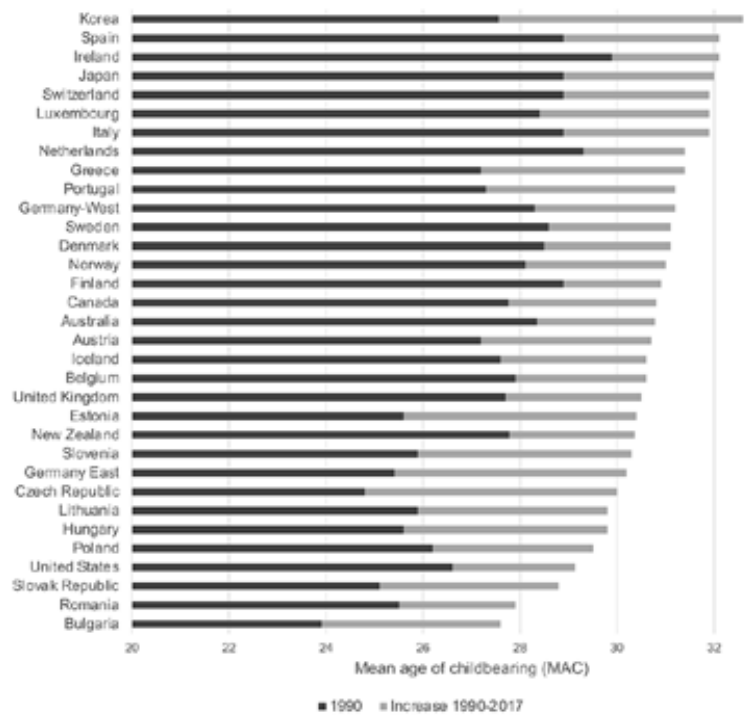

Note: For 2017, data for Australia and the United States refer to 2015, and data for Canada and New Zealand refer to 2016. For 1990, data for Korea refer to 1993.

Source: OECD Family Database (2019); Federal Institute for Population Research (2020). Own representation.

\section{Figure 26.3 Mean age of childbearing 1990 and 2017 in developed countries}

According to period calculations of age-specific first birth rates for the years 2012-14, 46 per cent of highly educated women had their first birth by age 35, 26 per cent had their first birth at age 35 or older, and another 28 per cent remained permanently childless (Bujard and Diabaté 2016). It is unclear how many of those women who remained childless did so unintentionally because of medical or social barriers. Collecting survey data on unintentional permanent childlessness is methodologically challenging. At some point, most people come to terms with their situation - in this case, with their childlessness - and their answers to survey questions reflect that acceptance. Measuring the life course experience of infertility could be an alternative approach to identifying people's paths into permanent childlessness in the context of medical barriers. While efforts to measure life course prevalence rates of infertility have many problems, it has been estimated that between one-third and two-thirds of all women experience infertility during their reproductive period.

\subsection{Contribution of Medically Assisted Reproduction to Fertility Measures}

We lack sufficient data to calculate the contribution of all MAR techniques to fertility. There are, however, data on the proportion of ART children per national births, which indicate that the average for European countries is 2.1 per cent (Geyter et al. 2018). These data do not cover ART treatments that took place in other countries, and potentially with methods that are not allowed in the country of residence. In 2014, ART contributed 6.4 per cent of births in Denmark and Spain; and between 5.4 and 5.9 per cent of births in Slovenia, Austria, the Czech Republic, and Greece (Figure 26.4). In Serbia, Lithuania, Romania, and Ireland, the 
contribution of ART was below 0.7 per cent. Projections for 2100 - which are, admittedly, speculative - suggest that by that year, between 1.4 and 3.5 per cent of the world's population will be born through ART (Faddy et al. 2018).

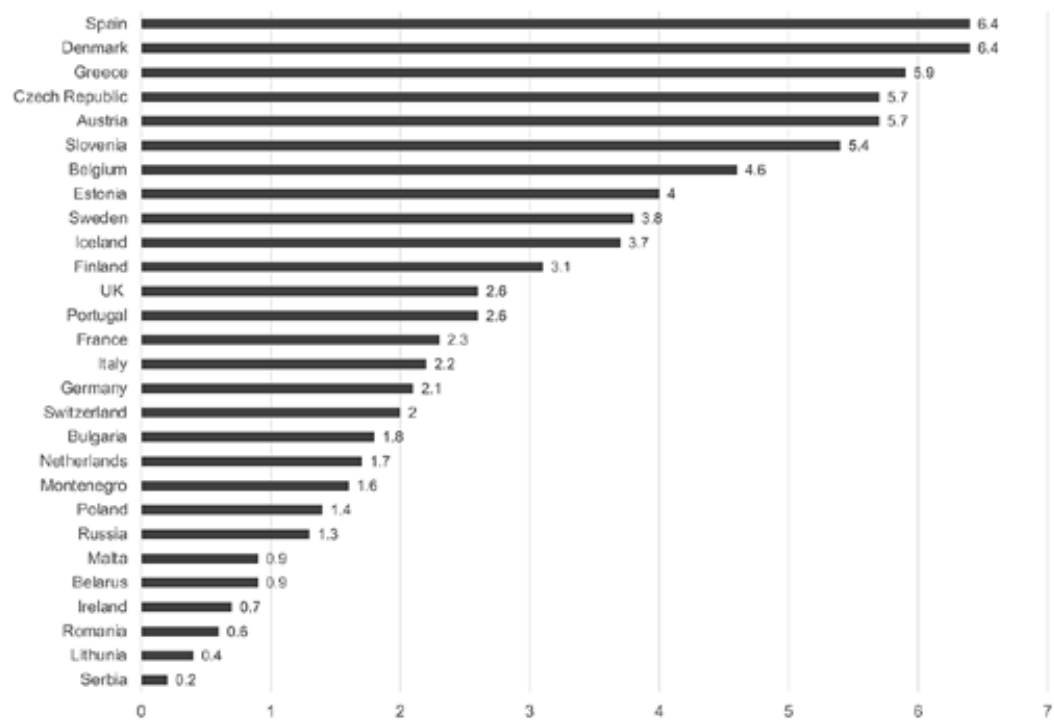

Note: ART includes IVF, ICSI, and FET.

Source: Geyter et al. (2018). Own representation.

Figure 26.4 Proportion of assisted reproductive technologies per births in European countries

The effect of MAR on fertility is complex. On the one hand, the use of MAR results in a specific number of births for infertile couples; on the other hand, people might incorporate the option of using MAR in their long-term fertility plans, and thus delay childbirth. However, the use of ART does not guarantee pregnancy, much less the birth of a child. The mean pregnancy rate over all European countries after IVF treatment is 29 per cent, and it is 27 per cent for ICSI (Geyter et al. 2018). Delivery rates are 22 per cent for IVF and 20 per cent for ICSI. Pregnancy and delivery rates strongly depend on age. The IVF pregnancy rate is 30 per cent for women under age 35, is 25 per cent for women aged 35 to 39, and decreases to 14 per cent for women aged 40 or older (Geyter et al. 2018). The success of ART is often overrated. Respondents of a web survey in six European countries estimated that the IVF success rate is 47 per cent (Fauser et al. 2019).

Another perspective on the value of ART for fertility is to estimate how many years of postponement are feasible while realising a specific number of desired children if the success rates of IVF are taken into account. The gain of years for those who intend to use IVF was simulated for different parities and chances of realisation by Habbema et al. (2015). They estimated that to have a 75 per cent chance of realising a two-child family without IVF, a couple would have to start their family at a maximum female age of 34; and that to have the same chances with IVF, the couple would have to start their family at a maximum female age of 35 . 
The maximum age to realise three children is 31 without and 33 with IVF. Thus, because the success rates are lower than many people expect, the 'time gained' by ART is very little. It has been shown that the availability of ART encourages women and men to delay conception (Fauser et al. 2019). Therefore, a MAR-fertility paradox emerges: i.e., the effect of (implicitly) considering the opportunities of MAR on the postponement of family formation could reduce the total fertility rate even more than the MAR births increase the total fertility rate.

\section{SUMMARY AND KEY SOCIETAL CHALLENGES}

MAR is a dynamic field that has evolved rapidly in recent decades in terms of medical-technological development, and the demand for and access to treatments. We expect that all these factors will contribute to additional increases in the demand for and the usage of MAR in the future. In developed countries, the demand will further increase due to the postponement of births to ages above 35 where the risk of experiencing age-related infertility increases considerably. There are, however, substantial differences in the use of MAR across developed countries: the share of ART births ranges from less than 1 per cent to more than 6 per cent. The share would be even higher if the broader term MAR was used, and treatments such as assisted inseminations were included. MAR is having a large impact on individuals and societies: new family forms are appearing; social inequalities in out-of-pocket expenses and access to treatment are emerging; and biographical plans regarding the timing of fertility are changing. From our overview on MAR in developed countries, we draw six conclusions.

Reproductive medicine is more than ART. The terms ART and IVF are often used interchangeably. Indeed, IVF is the core ART treatment, and other ART treatments - such as oocyte donation, PGT, or social freezing - are based on it or related to it. However, the term ART does not cover assisted inseminations, hormonal therapies, or other interventions that are frequently applied in the treatment of individuals or couples. Assisted inseminations and hormonal therapies are less invasive, less costly, and have few side effects - and they might be as effective as ART in helping women or couples have their intended number of children. The utilisation of the term MAR is not only more comprehensive; it paves the way for recording the use of medical reproduction more accurately in surveys and analyses.

There is no simple solution to the moral and ethical issues involved in national legislative processes regarding MAR. Across developed countries, the laws regulating MAR differ not only in terms of which methods are allowed, but in terms of how the methods are applied, who has access to them, and how they are reimbursed. Oocyte donation is permitted under specific conditions in most developed countries. Surrogacy is allowed in only some countries, and in these countries the rules regarding the payment of the surrogate, the definition of altruistic surrogacy, and the rights of the surrogate and of the commissioning parents differ. The diagnostic treatment PGT is permitted in most countries, sex selection is allowed only in some countries, and SFR is allowed in most countries, but often under specific conditions. These national differences reflect differences in how general moral values and ethical considerations are weighed in national legislative processes. Moreover, the decisions on who is supported in their attempt to have a child reflect normative expectations regarding acceptable ways of building a family and acceptable family forms.

Cross-border reproductive care challenges MAR users and societies. Each country has its own legal regulations, but the use of technologies such as MAR is not bound by country 
borders. More and more people now travel abroad to obtain lower-priced treatments, or to gain access to methods that are not allowed in their home country, or that they are excluded from accessing. However, knowledge about the magnitude of cross-border reproductive care around the globe, and about who is using it, remains limited. For prospective parents, making decisions about seeking medical help becomes much more complex if reproductive travelling has to be considered.

Cross-border reproductive care represents a challenge to the thinking of courts, social scientists, and policy-makers. Its use can result in complicated legal issues when, for example, it comes to legalising families that were created in another national context where oocyte donation or surrogacy is allowed. The 'new families' created with the help of treatments such as surrogacy or oocyte donation challenge local authorities with their requests to legalise their status as a family. It has been argued that the increasing visibility of new family forms could initiate changes in domestic laws in a bottom-up process (Naldini and Long 2017) that unfolds over the medium to long term. Social scientists should respond to these social changes in their research. We need more knowledge about the empirical relevance of 'new families' created with medical help in the home country or abroad. Moreover, we should seek to learn more about the experiences of these families during their 'reproductive journeys'. In addition, we should seek to better understand what the consequences of these journeys are, especially for the health of women in poorer countries who are surrogates or donate their oocytes, and for global social inequalities.

Country differences in legislation and reimbursement raise social inequalities. In most developed countries, at least some of the medical costs of treatment are publicly funded. There are often restrictions on funding based on the age of the prospective mother and parity. Policies vary regionally in some countries. Moreover, funding is often provided for specific treatments only, and the number of treatment cycles an individual can receive is usually limited. Out-of-pocket expenses can be considerable. Hence, prospective parents with higher incomes and better education tend to have better access to MAR treatments than their lower-income counterparts. The reimbursement issue is ethically challenging, because in several cases MAR treatments are not related to an illness. This is especially the case for social freezing, as most of the women who use this service are making a private decision to postpone getting pregnant to higher and less fertile ages.

The interrelation of MAR and demographic behaviour is not straightforward. The MARfertility paradox implies that the continuing postponement of births to higher ages and the increasing use of MAR go hand in hand. The postponement trend increases the demand for MAR, especially among highly educated couples, who often have the high income needed to enable them to finance fertility treatments. There are clear hints that people overestimate the success rates of MAR, especially for older women. The availability of MAR may increasingly become part of people's fertility plans over the life course, which could result in a MAR-fertility paradox emerging in the future. The effect of MAR on completed fertility could decrease because the negative effect of planning with MAR could be even greater than the number of MAR babies who will be born. In any case, the interrelations of MAR and life course decisions should be analysed carefully in the future, and education about fertility should be improved.

Limited knowledge of the implications of using MAR for prospective parents and children. While MAR can represent a solution for people who face medical or social barriers to meeting their fertility goals, the risk of failure is non-negligible. It is important to keep this risk in mind 
when talking about the 'costs' of treatment, which are not just financial in nature. Fertility treatments can be physically and psychologically stressful for those who use them, with women being more affected than men. Knowledge about the implications of treatments for the families and children created with MAR is starting to accumulate. Overall, it appears that MAR is not harmful for the health and social-psychological outcomes of the children born through such treatments. Child welfare is not directly affected by the structure or the type of family a child is born into. However, there is a need for more research on the long-term effects that is designed to control for important confounders. Beyond that, studying 'MAR families' provides researchers with an opportunity to examine the effects of family structure and family processes in traditional and non-traditional families.

\section{NOTE}

1. In traditional surrogacy, the surrogate's own egg is fertilised in vivo, usually with the help of assisted insemination.

\section{REFERENCES}

Adamson, G.D., J. de Mouzon, G.M. Chambers, F. Zegers-Hochschild, R. Mansour, and O. Ishihara (2018), 'International committee for monitoring assisted reproductive technology: World report on assisted reproductive technology, 2011', Fertility and Sterility, 110 (6), 1067-80. doi:10.1016/j .fertnstert.2018.06.039.

Billari, F., C. Liefbroer, C. Aart, and D. Philipov (2006), 'The postponement of childbearing in Europe: Driving forces and implications', Vienna Yearbook of Population Research, 4, 1-17.

Boundy, K. (2019), 'How is IVF funded across the world?', accessed 25 May 2020 at www.ivfbabble .com/2019/09/ivf-funded-across-world.

Brkovich, A.M. and W.A. Fisher (2009), 'Psychological distress and infertility: Forty years of research', Journal of Psychosomatic Obstetrics and Gynecology, 19 (4), 218-28. doi:10.3109/ 01674829809025700 .

Buchholz, S., D. Hofäcker, M. Mills, H.-P. Blossfeld, K. Kurz, and H. Hofmeister (2008), 'Life courses in the globalization process: The development of social inequalities in modern societies', European Sociological Revue, 25 (1), 53-71. doi:10.1093/esr/jen033.

Bujard, M. and S. Diabaté (2016), 'Wie stark nehmen Kinderlosigkeit und späte Geburten zu?', Der Gynäkologe, 49 (5), 393-404. doi:10.1007/s00129-016-3875-4.

Calhaz-Jorge, C., C. de Geyter, M.S. Kupka, J. de Mouzon, K. Erb, E. Mocanu et al. (2016), 'Assisted reproductive technology in Europe, 2012: Results generated from European registers by ESHRE', Human Reproduction, 31 (8), 1638-52. doi:10.1093/humrep/dew151.

Calhaz-Jorge, C., C. de Geyter, M.S. Kupka, J. de Mouzon, K. Erb, E. Mocanu et al. (2017), 'Assisted reproductive technology in Europe, 2013: Results generated from European registers by ESHRE', Human Reproduction, 32 (10), 1957-73. doi:10.1093/humrep/dex264.

Calhaz-Jorge, C., C. de Geyter, M.S. Kupka, C. Wyns, E. Mocanu, T. Motrenko, G. Scaravelli, J. Smeenk, S. Vidakovic, and V. Goossens (2020), 'Survey on ART and IUI: Legislation, regulation, funding and registries in European countries: The European IVF-monitoring Consortium (EIM) for the European Society of Human Reproduction and Embryology (ESHRE)', Human Reproduction Open, 1, hoz044, 1-15. doi:10.1093/hropen/hoz044.

Chambers, G.M., V. Hoang, R. Zhu, and P.J. Illingworth (2012), 'A reduction in public funding for fertility treatment: An econometric analysis of access to treatment and savings to government', $B M C$ Health Service Research, 12 (1). doi:10.1186/1472-6963-12-142. 
Crawford, G.E. and W.L. Ledger (2019), 'In vitro fertilisation/intracytoplasmic sperm injection beyond 2020', BJOG: International Journal of Obstetrics and Gynaecology, 126 (2), 237-43. doi:10.1111/ 1471-0528.15526.

Culley, L., N. Hudson, and M. Lohan (2013), 'Where are all the men? The marginalization of men in social scientific research on infertility', Reproductive Biomedicine Online, 27 (3), 225-35. doi:10 $.1016 /$ j.rbmo.2013.06.009.

Datta, J., M.J. Palmer, C. Tanton, L.J. Gibson, K.G. Jones, W. Macdowall et al. (2016), 'Prevalence of infertility and help seeking among 15000 women and men', Human Reproduction, 31 (9), 2108-18. doi:10.1093/humrep/dew123.

Dunson, D.B., D.D. Baird, and B. Colombo (2004), 'Increased infertility with age in men and women', Obstetrics and Gynecology, 103 (1), 51-6. doi:10.1097/01.AOG.0000100153.24061.45.

Faddy, M.J., M.D. Gosden, and G. Roger (2018), 'A demographic projection of the contribution of assisted reproductive technologies to world population growth', Reproductive Biomedicine Online, 36 (4), 455-8. doi:10.1016/j.rbmo.2018.01.006.

Farland, L.V., A.-R.Y. Collier, K.F. Correia, F. Grodstein, J.E. Chavarro, J. Rich-Edwards, and S.A. Missmer (2016), 'Who receives a medical evaluation for infertility in the United States?', Fertility and Sterility, 105 (5), 1274-80. doi:10.1016/j.fertnstert.2015.12.132.

Fauser, B.C.J.M., J. Boivin, P.N. Barri, B.C. Tarlatzis, L. Schmidt, and R. Levy-Toledano (2019), 'Beliefs, attitudes and funding of assisted reproductive technology: Public perception of over 6,000 respondents from 6 European countries', PloS One, 14 (1), e0211150. doi:10.1371/journal.pone .0211150

Federal Institute for Population Research (2020), Durchschnittliches Alter der Mütter bei Geburt ihrer Kinder in Deutschland, accessed 29 May 2020 at https://www.bib.bund.de/DE/Fakten/Fakt/F18-Alter -Muetter-bei-Geburt-Deutschland-West-Ost-ab-1960.html?nn=9992014.

Ferraretti, A.P., G. Pennings, L. Gianaroli, F. Natali, and M.C. Magli (2010), 'Cross-border reproductive care: A phenomenon expressing the controversial aspects of reproductive technologies', Reproductive Biomedicine Online, 20 (2), 261-6. doi:10.1016/j.rbmo.2009.11.009.

Geyter, C. de, C. Calhaz-Jorge, M.S. Kupka, C. Wyns, E. Mocanu, T. Motrenko, G. Scaravelli, J. Smeenk, S. Vidakovic, V. Goossens, and European IVF-monitoring Consortium for the European Society of Human Reproduction and Embryology (2018), 'ART in Europe, 2014: Results generated from European registries by ESHRE', Human Reproduction, 33 (9), 1586-601. doi:10.1093/humrep/ dey242.

Golombok, S. (2015), Modern Families: Parents and Children in New Family Forms, Cambridge: Cambridge University Press.

Greil, A.L. (1997), 'Infertility and psychological distress: A critical review of the literature', Social Science and Medicine, 45 (11), 1679-704. doi:10.1016/S0277-9536(97)00102-0.

Greil, A.L., K.M. Shreffler, L. Schmidt, and J. McQuillan (2011a), 'Variation in distress among women with infertility: Evidence from a population-based sample', Human Reproduction, 26 (8), 2101-12. doi:10.1093/humrep/der148.

Greil, A.L., J. McQuillan, M. Lowry, and K.M. Shreffler (2011b), 'Infertility treatment and fertility-specific distress: A longitudinal analysis of a population-based sample of US women', Social Science and Medicine, 73 (1), 87-94. doi:10.1016/j.socscimed.2011.04.023.

Guilmoto, C.Z. and G. Duthé (2013), 'Masculinization of births in Eastern Europe', Population and Societies, 506, 1-4.

Habbema, D., M. Eijkemans, H. Leridon, and E.R. te Velde (2015), 'Realizing a desired family size: When should couples start?', Human Reproduction, 30 (9), 2215-21. doi:10.1093/humrep/dev148.

Halliday, J. (2007), 'Outcomes of IVF conceptions: are they different?', Best Practice and Research Clinical Obstetrics and Gynaecology, 21 (1), 67-81. doi:10.1016/j.bpobgyn.2006.08.004.

Hart, R. and R.J. Norman (2013a), 'The longer-term health outcomes for children born as a result of IVF treatment. Part I: General health outcomes', Human Reproduction Update, 19 (3), 232-43. doi:10 .1093/humupd/dms062.

Hart, R. and R.J. Norman (2013b), 'The longer-term health outcomes for children born as a result of IVF treatment. Part II: Mental health and development outcomes', Human Reproduction Update, 19 (3), 244-50. doi:10.1093/humupd/dmt002. 
Helmerhorst, F.M., D.A.M. Perquin, D. Donker, and M.J.N.C. Keirse (2004), 'Perinatal outcome of singletons and twins after assisted conception: A systematic review of controlled studies', British Medical Journal, 328. doi:10.1136/bmj.37957.560278.EE.

Human Fertilisation and Embryology Authority (2020), Costs and Funding, accessed 25 May 2020 at www.hfea.gov.uk/treatments/explore-all-treatments/costs-and-funding.

IFFS (International Federation of Fertility Societies' Surveillance) (2016), 7th edition, Global Reproductive Health, 1 (e1), 1-143. doi:10.1097/GRH.0000000000000001.

IFFS (International Federation of Fertility Societies' Surveillance) (2019), 'Global trends in reproductive policy and practice', 8th edition, Global Reproductive Health 4 (1), e29. doi:10.1097/GRH .0000000000000029 .

Ilioi, E.C. and S. Golombok (2015), 'Psychological adjustment in adolescents conceived by assisted reproduction techniques: A systematic review', Human Reproduction Update, 21 (1), 84-96. doi:10 .1093/humupd/dmu051.

Kocourkova, J., B. Burcin, and T. Kucera (2014), 'Demographic relevancy of increased use of assisted reproduction in European countries', Reproductive Health, 11 (1). doi:10.1186/1742-4755-11-37.

Kreyenfeld, M. (2010), 'Uncertainties in female employment careers and the postponement of parenthood in Germany', European Sociological Review, 26 (3), 351-66. doi:10.1093/esr/jcp026.

Kreyenfeld, M. and D. Konietzka (eds) (2017), Childlessness in Europe: Contexts, Causes, and Consequences, Dordrecht: Springer.

Lesthaeghe, R. (2010), 'The unfolding story of the second demographic transition', Population and Development Review, 36 (2), 211-51. doi:10.1111/j.1728-4457.2010.00328.x.

Ludwig, A.K., A.G. Sutcliffe, K. Diedrich, and M. Ludwig (2006), 'Post-neonatal health and development of children born after assisted reproduction: A systematic review of controlled studies', European Journal of Obstetrics and Gynecology and Reproductive Biology, 127 (1), 3-25. doi:10 .1016/j.ejogrb.2006.02.009.

Mains, L., M. Zimmerman, J. Blaine, B. Stegmann, A. Sparks, T. Ansley, and B. van Voorhis (2010), 'Achievement test performance in children conceived by IVF', Human Reproduction, 25 (10), 2605-11. doi:10.1093/humrep/deq218.

Markmeyer, B. (2019), 'Wie viele Anträge auf eine PID gibt es jedes Jahr? Umfrage bei den zuständigen Ethikkommissionen. EPD', accessed 30 March 2020 at www.evangelisch.de/inhalte/154879/ 30-01-2019/weniger-als-350-antraege-auf-eine-pid-pro-jahr?kamp=b-012.

Naldini, M. and J. Long (2017), 'Geographies of families in the European Union: A legal and social policy analysis', International Journal of Law, Policy and the Family, 31 (1), 94-113. doi:10.1093/ lawfam/ebw017.

Neels, K., M. Murphy, M. Ní Bhrolcháin, and É. Beaujouan (2017), 'Rising educational participation and the trend to later childbearing', Population and Development Review, 43 (4), 667-93. doi:10.1111/ padr.12112.

Nuffield Council on Bioethics (2013), Donor Conception: Ethical Aspects of Information Sharing, accessed 17 July 2020 at www.nuffieldbioethics.org/publications/donor-conception.

OECD Family Database (2019), SF2.3: Age of Mothers at Childbirth and Age-Specific Fertility, accessed 29 May 2020 at www.oecd.org/els/family/database.htm.

Passet-Wittig, J. (2017), Unerfüllte Kinderwünsche und Reproduktionsmedizin. Eine sozialwissenschaftliche Analyse von Paaren in Kinderwunschbehandlung, Opladen: Verlag Barbara Budrich.

Passet-Wittig, J., M. Bujard, J. McQuillan, and A.L. Greil (2020), 'Is perception of inability to procreate a temporal phenomenon? A longitudinal exploration of changes and determinants among women and men of reproductive age in Germany', Advances in Life Course Research, 45, (100339). doi:10.1016/ j.alcr.2020.100339.

Passet-Wittig, J. and A.L. Greil (2021), 'Factors associated with medical help-seeking for infertility in developed countries: A narrative review of recent literature', Social Science and Medicine, online (113782). doi:10.1016/j.socscimed.2021.113782

Pavone, V. and F. Arias (2012), 'Beyond the geneticization thesis: The political economy of PGD/PGS in Spain', Science, Technology and Human Values, 37, 235-61. doi:10.2307/41511173.

Pennings, G. (2002), 'Reproductive tourism as moral pluralism in motion', Journal of Medical Ethics, 28, 337-41. doi:10.1136/jme.28.6.337. 
Pennings, G. (2009), 'International evolution of legislation and guidelines in medically assisted reproduction', Reproductive Biomedicine Online, 18 (Supplement 2), 15-18. doi:10.1016/S1472-6483( 10)60443-9.

Präg, P. and M.C. Mills (2017), 'Cultural determinants influence assisted reproduction usage in Europe more than economic and demographic factors', Human Reproduction, 32 (11), 2305-14. doi:10.1093/ humrep/dex298.

Rockliff, H.E., L. Lightman, E. Rhidian, H. Buchanan, U. Gordon, and K. Vedhara (2014), 'A systematic review of psychosocial factors associated with emotional adjustment in in vitro fertilization patients', Human Reproduction Update, 20 (4), 594-613. doi:10.1093/humupd/dmu010.

Salama, M., V. Isachenko, E. Isachenko, G. Rahimi, P. Mallmann, L.M. Westphal et al. (2018), 'Cross border reproductive care (CBRC), a growing global phenomenon with multidimensional implications (a systematic and critical review)', Journal of Assisted Reproduction and Genetics, 35, 1277-88. doi: 10.1007/s10815-018-1181-x.

Verhaak, C.M., J.M.J. Smeenk, A.W.M. Evers, J.A.M. Kremer, F.W. Kraaimaat, and D.D.M. Braat (2007), 'Women's emotional adjustment to IVF: A systematic review of 25 years of research', Human Reproduction Update, 13 (1), 27-36. doi:10.1093/humupd/dml040.

Wagenaar, K., J. Huisman, P.T. Cohen-Kettenis, and H.A. Delemarre-van de Waal (2008), 'An overview of studies on early development, cognition, and psychosocial well-being in children born after in vitro fertilization', Journal of Developmental and Behavioral Pediatrics, 29 (3), 219-30. doi:10.1097/DBP $.0 \mathrm{~b} 013 \mathrm{e} 318173 \mathrm{a} 575$.

Warnock, M. (2002), Making Babies: Is There a Right to Have Children?, Oxford: Oxford University Press.

Wischmann, T. and P. Thorn (2013), '(Male) infertility: What does it mean to men? New evidence from quantitative and qualitative studies', Reproductive Biomedicine Online, 27 (3), 236-43. doi:10.1016/ j.rbmo.2013.06.002.

Wu, A.K., P. Elliott, P.P. Katz, and J.F. Smith (2013), 'Time costs of fertility care: The hidden hardship of building a family', Fertility and Sterility, 99 (7), 2025-30. doi:10.1016/j.fertnstert.2013.01.145.

Ying, L.Y., L.H. Wu, and A.Y. Loke (2015), 'Gender differences in experiences with and adjustments to infertility: A literature review', International Journal of Nursing Studies, 52 (10), 1640-52. doi:10 .1016/j.jinurstu.2015.05.004.

Ying, L., L.H. Wu, and A.Y. Loke (2016), 'Gender differences in emotional reactions to in vitro fertilization treatment: A systematic review', Journal of Assisted Reproduction and Genetics, 33 (2), 167-79. doi:10.1007/s10815-015-0638-4.

Zadeh, S., E.C. Ilioi, V. Jadva, and S. Golombok (2018), 'The perspectives of adolescents conceived using surrogacy, egg or sperm donation', Human Reproduction, 33 (6), 1099-106. doi:10.1093/ humrep/dey088.

Zegers-Hochschild, F., G.D. Adamson, S. Dyer, C. Racowsky, J. de Mouzon, R. Sokol, L. Rienzi, A. Sunde, L. Schmidt, I.D. Cooke, J.L. Simpson, and S. van der Peol (2017), 'The international glossary on infertility and fertility care, 2017', Human Reproduction, 32 (9), 1786-801. doi:10.1093/humrep/ $\operatorname{dex} 234$. 